\title{
The emotional heart: prospective associations of anger, depression, and anxiety as risk factors for myocardial infarction in a 22-year follow-up of a working cohort of middle-aged men
}

\author{
Rebecca Vella ${ }^{1}$ (D) $\cdot$ Richard P. Sloan ${ }^{2} \cdot$ Bo Eriksson $^{3} \cdot$ Lennart Dimberg $^{1}$ (D)
}

Received: 2 December 2020 / Accepted: 17 May 2021 / Published online: 7 June 2021

(C) The Author(s) 2021

\begin{abstract}
Aim The study aim was to further clarify the relationship between psychological factors and myocardial infarction (MI) by simultaneously examining anger, depression, and anxiety as risk factors for incident $\mathrm{MI}$ in a healthy working sample.

Subject and method Baseline measurements of psychological variables were assessed through a self-reported questionnaire in a healthy cohort of 968 middle-aged men working at the Volvo Corporation. Single-item questions assessed depression and anxiety. Anger was assessed by the Trait Anger subscale of the Spielberger State-Trait Anger Expression Inventory. The endpoint was incident MI verified by national registers or medical records with follow up after 22 years. The main outcome was computed through logistic regression, reported as odds ratios. Additional correlation analyses were performed between psychological variables and coronary risk factors.

Results None of the psychological variables was significantly associated with the outcome; thus, the results failed to show an association between anger, depression, or anxiety and incident MI in this sample. There were some significant, but weak, correlations between psychological factors and negative health behaviors. Other components of traditional risk scoring instruments did not correlate with the psychological factors.

Conclusion A cohort restricted to middle-age healthy men limits applicability. However, our failure to replicate earlier results of population samples suggests a need for further research on associations between psychological factors and MI in healthy samples.
\end{abstract}

Keywords Myocardial infarction $\cdot$ Anger $\cdot$ Depression $\cdot$ Anxiety $\cdot$ Cohort study

\section{Introduction}

Major known risk factors for coronary heart disease (CHD) include high blood pressure, smoking, dyslipidemia, diabetes, and obesity (Blaha et al. 2021; Hubert et al. 1983; Pencina et al. 2019). However, there is a gap between risk estimation and those affected by disease (Brindle et al. 2003, 2006; Hense et al. 2003) and, as a result, other possible predictors

Lennart Dimberg

lennart.dimberg@allmed.gu.se

1 Department of Public Health and Community Medicine, The Sahlgrenska Academy, University of Gothenburg, Box 454, SE-405 30 Gothenburg, Sweden

2 Division of Behavioral Medicine, Department of Psychiatry, Columbia University Irving Medical Center, New York, NY, USA

3 Department of Health Metrics, The Sahlgrenska Academy, University of Gothenburg, Gothenburg, Sweden for disease are investigated. In this context, the field of behavioral cardiology has been exploring connections between social environment, mood, and heart disease, pointing out several psychosocial stressors - for example, negative emotional states, social strain, and work stress - that are now considered probable additional risk factors for developing CHD (Das and O'Keefe 2006; Everson-Rose and Lewis 2005; Fishta and Backé 2015; Kivimäki et al. 2006; Rosengren et al. 2004; Rozanski et al. 2005). The proposed mechanisms behind them are an upregulation of the hypothalamic-pituitary-adrenal axis, a dysregulation of the autonomic nervous system, as well as altered behaviors coupled with psychosocial factors (Rozanski et al. 2005). The main goal of this study is to further examine three suggested psychological risk factors for CHD: depression, anxiety, and anger-hostility by studying them in a healthy working sample of middle aged men.

A growing body of research has focused on these three affective dispositions that seem to predict CHD (EversonRose and Lewis 2005). The most convincing evidence derives 
from prospective epidemiological cohort studies where depression, anxiety, and anger-hostility separately have been found to significantly associate with an increased risk for developing CHD in initially healthy populations and to similarly significantly associate with poorer prognosis in populations with pre-existing CHD (Celano et al. 2015, Chida and Steptoe 2009; Nicholson et al. 2006; Roest et al. 2010; Rozanski et al. 1999; Wu and Kling 2016). However, a number of individual studies have not shown any effect (Chida and Steptoe 2009; Janszky et al. 2010; Mykletun et al. 2007; Roest et al. 2010), and several meta-analyses have reached disparate conclusions regarding generalizability (Celano et al. 2015; Chida and Steptoe 2009, Nicholson et al. 2006; Roest et al. 2010; Wu and Kling 2016). However, other studies have linked depression, anxiety, and anger-hostility to several surrogate markers of $\mathrm{CHD}$, among these coronary artery calcification (Santos et al. 2016) and carotid intima-media thickness (Matthews et al. 1998; Pollitt et al. 2005; Räikkönen et al. 2004; Santos et al. 2015) as signs of subclinical atherosclerosis, and decreased heart rate variability (Chalmers et al. 2014; Kemp et al. 2012; Sloan et al. 1994; Suls 2013), implying autonomic dysregulation of the heart. Notably, anger and hostility represent different psychological constructs but are largely intertwined and have often been interchangeably used due to a lack of standard definition and the degree of overlap in-between them (Chida and Steptoe 2009; Everson-Rose and Lewis 2005; Martin et al. 2000; Schulman and Stromberg 2007; Suls 2013). For simplicity, the term "anger" will be applied here onward.

Current evidence singles out depression as the best studied and most robust association (Celano et al. 2015; Nicholson et al. 2006; Rozanski et al. 1999), with a 2016 meta-analysis reporting a CHD risk augmentation of $22 \%$ in originally healthy populations (Wu and Kling 2016). For comparison, a traditional risk factor such as smoking entails an excess risk starting at 50\% (Law and Wald 2003, U.S. Department of Health and Human Services 2010). Nevertheless, considering the substantial prevalence of depression, it thus appears as a contributory disease-driving element in a sizeable amount of CHD (Wu and Kling 2016). Some studies even report a doseresponse relationship, where higher levels of depressive symptoms seem to couple with a higher risk gradient for CHD outcomes, both in healthy persons (Barefoot and Schroll 1996; Brunner et al. 2014), and in patients post-MI (Lesperance et al. 2002). Other studies have suggested anxiety to be an affective component in the development of CHD (Chida and Steptoe 2009; Shen et al. 2008), amounting to an increased risk of $26 \%$ for those initially healthy in the most recent metaanalysis (Roest et al. 2010). Finally, for anger, a meta-analysis demonstrated an associated 19\% increase in risk of developing CHD in healthy populations. However, these findings were markedly mixed and the association for anger did not persist when controlling for covariates (Chida and Steptoe 2009).
Regrettably, literature provides little insight into whether these factors give rise to disease or if they simply act as risk markers for CHD, as common methodological problems in epidemiology limit assessment of causation. First, the temporal relationship between exposure and disease must be determined to confirm which condition preceded the other (Hill 1965). Considering that the pathogenesis of atherosclerosis is a decades-long process (Insull 2009), studies should ideally start with a relatively young and healthy sample and prospectively follow such a cohort for an extensive amount of time. The majority of studies to date have either had a crosssectional design or been prospective cohort studies with follow-ups of less than a decade. Many cohort studies have focused on elderly people (Chida and Steptoe 2009; Roest et al. 2010; Wu and Kling 2016) in whom, even if healthy in relation to manifest CHD, silent atherosclerosis is likely to be widespread at study entry (Insull 2009). Second, one needs to consider possible confounding factors (von Elm et al. 2008), a practice that has often been deficient (Chida and Steptoe 2009; Wu and Kling 2016), even though potential confounders are manifold in community samples (Chida and Steptoe 2009; Roest et al. 2010; Wu and Kling 2016). In this respect, it would be advantageous to begin with a more homogeneous healthy population. For example, only a small number of studies have examined any of these affects in a healthy working sample of a narrow age-interval (Albert et al. 2005; Brunner et al. 2014; Nicholson et al. 2005; Whang et al. 2009), and these have shown few significant associations. One exception is the longitudinal cohort Nurse's Health Study, in which depression was linked to CHD outcomes with an excess risk of 37\% (Whang et al. 2009). However, this relationship was strongest for fatal MI and sudden cardiac deaths, why authors speculated whether depression could have more of a proarrhythmic rather than an atherosclerotic effect.

Psychological constructs pose a problem when looking independently at these factors in relation to CHD. There is wellknown diagnostic overlap between anxiety and depression (Krueger, 1999; Mineka et al. 1998; Suls and Bunde 2005), which can cause misclassification. Furthermore, anger, anxiety, and depression have the tendency to cluster in the same individual (Suls and Bunde 2005). Despite this, the majority of studies to date focus on either one or two affects and suggest independent effects on CHD when it is largely unknown how much of the reported risks should be attributed to either depression, anger, or anxiety in isolation (Suls and Bunde 2005). In actuality, when this has been specifically explored, the considerable overlap between these affects was such that their joint aspects emerged as a more important risk factor than any of their unique dimensions (Boyle et al. 2006; Kubzansky et al. 2006), presenting with effect sizes varying between 23\% (Boyle et al. 2006) and 108\% (Kubzansky et al. 2006). Consistent with this, a common disease-driving element, or at least a general emotional cardio-toxic pathway, 
has been advanced as a more plausible model than one related to each single affect (Suls and Bunde 2005). Meanwhile, the evidence on the inter-relationship between these traits as risk factors for CHD, pointed out by Suls and Bunde (2005) as "a serious gap in literature," remains today particularly scarce.

This study emanates from the Renault-Volvo (R-V) Coeur Study, a prospective longitudinal study initiated in 1992 in collaboration between the two automotive companies. In brief, its initial main objective was to understand why France had significantly lower rates of CHD than many other Western countries when the French lifestyle itself contained some risk-aspects, what has been called a "French Paradox" (Simon et al. 1997; Tunstall-Pedoe 1988; Tunstall-Pedoe et al. 1994). This current study is a 22-year follow-up limited to the Swedish Volvo cohort from the R-V Coeur Study, using a prospective longitudinal approach. The general aim is to further investigate anger, depression, or anxiety as risk factors for developing coronary heart disease by attempting to overcome some methodological limitations of the past, with the specific aim to study these factors simultaneously in a homogeneous healthy sample.

\section{Methods}

This study emanates from the R-V Coeur Study, the original study design of which has already been elaborately reported in previous publications (Denarié et al. 2001; Dimberg et al. 2019; Kumlin et al. 1997, 2001; Rose et al. 1998, 2006; Simon et al. 1997).

\section{Ethical considerations}

The Research Ethics Committee of Gothenburg University approved the original study protocol and the consent to participate form on 11 February 1993 (Dnr. 23-93). This study was performed in line with the principles of the Declaration of Helsinki. For the present study, a cover letter reminded participants of their participation in the R-V Coeur Study, stated the aims of the follow up, and emphasized that continued participation was voluntary and confidential. A form of written consent asked participants to approve validation of reported health information by use of medical records. The study reporting was executed in line with STROBE guidelines for observational studies.

\section{Participants}

This study reports only on the Swedish cohort from the original R-V Coeur Study. In 1993, a source population of all male workers born between 1943 and 1948 at participating plants of the Volvo Corporation were randomly screened for participants (see Fig. 1). Using date of birth, men born in a segment of the month (15-31) were selected to render a list from which identified participants were successively approached and requested to enroll. The sample size was set to 1000 participants for each country, chosen to within $90 \%$ probability detect a $20 \%$ difference in CHD endpoints between the Swedish and the French cohorts after 10 years. Given that men in this age group have twice the risk of developing CHD compared to women, the sample was limited to men to ensure a sufficient amount of endpoint events at follow up. Of the potential Swedish participants, 144 declined participation for a variety of reasons reported elsewhere (Simon et al. 1997), and a total of 1000 men in the age segment $45-50$ years were finally recruited. Among these, 23 participants were missing baseline data and 9 reported $\mathrm{CHD}$ at baseline and were therefore excluded from the present study, leaving a total of 968 for analysis.

\section{Procedure and settings}

At study baseline in 1993 (T1), all enrolled participants were invited to an appointment set during working hours. Participants were first administered a self-reported questionnaire on medical history, lifestyle factors, working conditions, and psychological characteristics. Next, they underwent an extensive nurse-administered health examination covering traditional CHD-related risk factors using blood pressure, resting electrocardiogram (ECG), anthropometrics, and a fasting venous blood sample. For the 2015 follow up (T2), a study form including five questions covering current or past heart disease or stroke was sent to participants' home addresses. History of MI was identified through the statement "I have suffered a heart attack" (yes/no). To verify self-reported events, an additional free-text statement read "I have been cared for in the following hospital or health care facility for the abovementioned condition." As an incentive for participation, 20 scratch lottery tickets were randomly distributed among the respondents. A survey reminder was sent out in week 4. Data collection ended after 5 weeks. Self-reported events of MI were subsequently verified through medical records. Both self-reported events and events among non-responders were verified against SWEDEHEART (2017), a national registry for MIs collecting data from all Swedish hospitals caring for patients with acute CHD as far back as 1991. For non-responders, MIs were additionally mapped using the Swedish National Board on Health and Welfare's National Cause of Death Registry.

\section{Variables}

\section{T1 exposure to psychological factors}

All psychological factors were assessed by self-reports at T1. Due to cultural reasons, depression and anxiety were each evaluated through single-item questions, modified from 
Fig. 1 Study flowchart presenting participant randomization,

recruitment, and inclusion as well as loss of participants at each level of the study

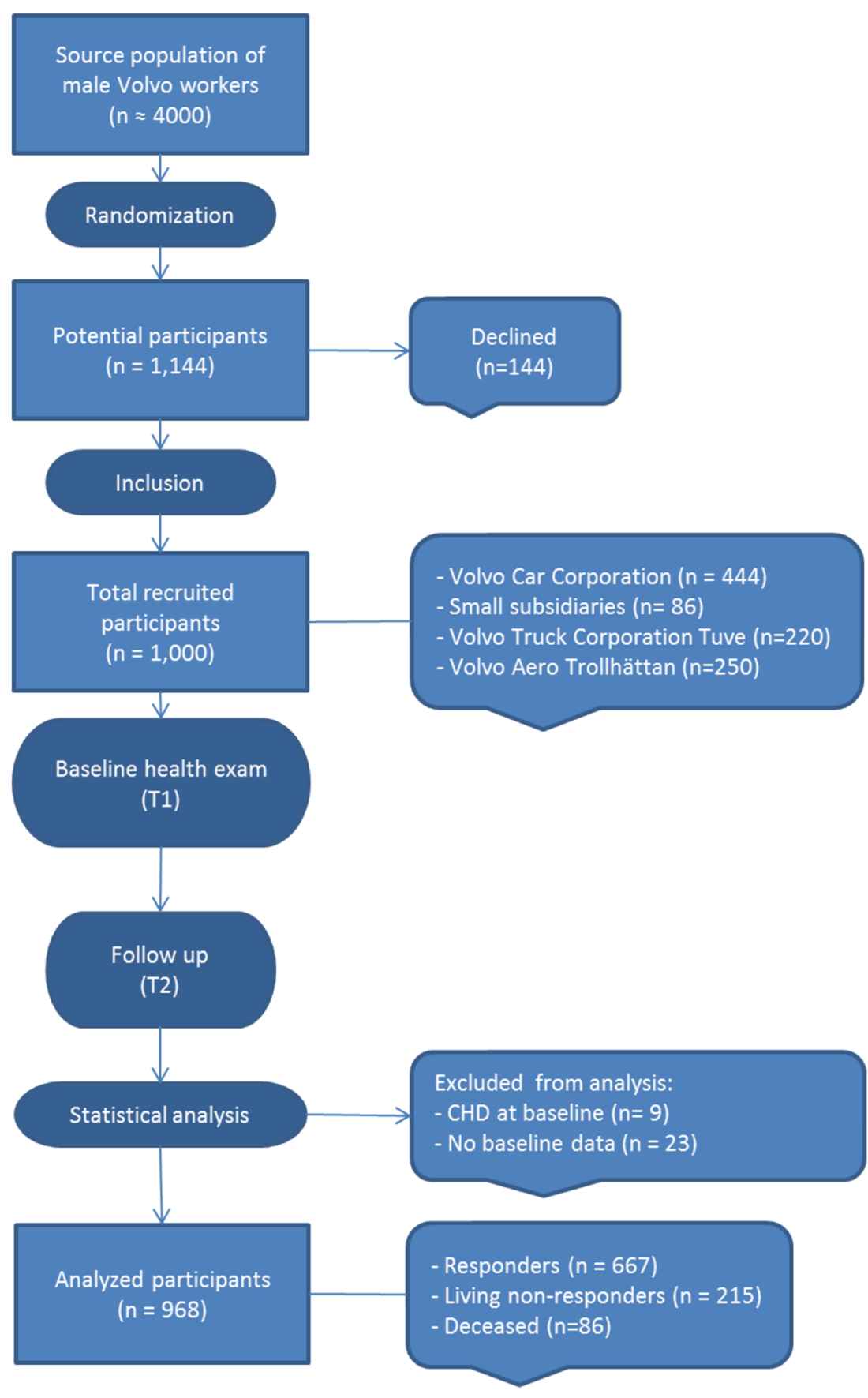

validated and widely used psychological instruments previously applied in CHD research, the Beck Depression Inventory (Beck 1987; Beck et al., 1988; Nicholson et al. 2006) and the Spielberger State-Trait Anxiety Inventory (STAI) (Elwood et al. 2012; Gafarov et al. 2007; Spielberger et al. 1983). Depression was assessed with "How often do you feel unhappy, depressed, or sad?", and anxiety evaluated by "How often do you feel fidgety, nervous, or tense?", both answered on a 9-point Likert type scale ranging from "never" to "always." Separately, anger was assessed with the Trait
Anger subscale of the State-Trait Anger Expression Inventory (STAXI) (Spielberger, 1988), which has previously linked anger to both CHD (Mendes de Leon et al. 1996; Williams et al. 2000) and its subclinical markers (Bleil et al. 2004; Matthews et al. 1998). Trait Anger is comprises 10 items evaluating disposition to experience anger and how this feeling manifests (Forgays et al. 1997) with items answered on a 4-point Likert scale ranging from "almost never" to "almost always" (Spielberger, 1988). For analysis, a sum anger score was generated, range 10-40. 


\section{T2 endpoint variable: myocardial infarction}

The outcome was MI, defined as a verified incident event of MI that occurred between T1 and T2. The diagnostic definition of myocardial infarction was International Classification of Diseases ninth version (ICD-9) code 410, or International Classification of Diseases tenth version (ICD-10) code I21I23 (World Health Organization 2017). For living responding participants, survey-reports of MI were verified through medical records or SWEDEHEART, or if not verifiable trough these sources, by a confirmative telephone call to the affected participant $(n=5)$. For non-responders, MIs were assessed directly through SWEDEHEART and the Swedish National Cause of Death Registry.

\section{Covariates}

The following variables were proposed as plausible covariates for found associations. As referenced, the details of these measures have already been carefully reported elsewhere.

Demographics Age at study entry, marital status, level of education, white or blue collar work (Dimberg et al. 2019).

Biological factors The Framingham risk index (FRI), calculated according to Anderson et al. (1991), obesity assessed through the body mass index (BMI) $\left(\mathrm{kg} / \mathrm{m}^{2}\right)$ (Simon et al. 1997).

Health behaviors Smoking in pack-years (Kumlin et al. 2001; Rose et al. 1998; Simon et al. 1997), alcohol intake in gram/day (Simon et al. 1997), social support as a global social support network index (Kumlin et al. 2001), physical exercise as hours per week (Rose et al. 1998).

\section{Statistical methods}

Data were coded and compiled into an SPSS file providing the basis for all statistical analyses. Simple statistics using means for continuous variables and percentages for dichotomous variables were used to report baseline participant characteristics for all participants as well as for responders, living non-responders, and deceased participants at follow up. Binary logistic regression models were applied to explore the associations between the suspected psychological risk factors at baseline as independent continuous variables and incident $\mathrm{MI}$ as the outcome dependent dichotomous variable. The main output was reported as odds ratios with confidence intervals and $p$ values within $95 \%$ probability limits. Significant associations were set to be controlled for possible confounding factors presented above using multivariate regression models. Correlation analyses were performed between the psychological variables and CHD covariates, reported as Pearson correlation coefficients (r) with their $p$ values within $95 \%$ or greater probability limits.

\section{Results}

\section{T1: baseline characteristics}

Out of the 1000 men enrolled, 9 participants reported CHD at T1 (angina $n=7$, heart disease $n=3$ ) and an additional 23 participants lacked baseline information, which excluded them from the data set, thereby leaving a total of 968 men for subsequent analyses. Among these, the majority $(61 \%)$ performed clerical (white-collar) work at Volvo and were either married or cohabitating $(76 \%)$ at study start. A smaller proportion had a university level education (24\%). Mean body mass index (BMI) was 25.6, 28\% were active smokers, 9.4\% had hypertension and the group had an average 9.1\% 10-year risk of CHD as assessed by the Framingham risk index. The mean ( \pm standard deviation) score for each of the psychological variables reported at $\mathrm{T} 1$ were $3.2 \pm 1.4$ for depression, 3.9 \pm 1.6 for anxiety, and $16.4 \pm 4.0$ for anger. Full baseline characteristics are reported in Table 1.

\section{Reports of incident MI}

Over 22 years, there were 84 cases of incident MI, affecting $8.7 \%$ of the entire cohort. In this subgroup, further introduced in Table 1, a larger proportion performed manual work at Volvo (49\%) at T1, and a lesser proportion had a university education (14\%) compared to those who were free of MI at follow up. Furthermore, their mean BMI was 26.7, 44\% were smokers, $16 \%$ had hypertension, and the average Framingham risk index 10-year risk was $13.6 \%$. Additionally, among those who later had an MI, mean alcohol consumption per week was higher, and somewhat fewer men performed regular physical exercise compared to those who did not have an MI. Figure 2 illustrates the estimated cumulative incidence of incident myocardial infarction by age in the entire original cohort of 980 men with baseline data (i.e., including those with CHD at T1) observed during the 22-year follow-up.

\section{Responding status at $\mathrm{T} 2$}

Baseline characteristics were further subdivided according to responding status at $\mathrm{T} 2$, as seen in Table 2 . Notably, in the group with deceased participants, prevalence of diabetes and hypertension was higher than for the other two, and $49 \%$ reported active smoking at $\mathrm{T} 1$. More men in this subgroup performed manual work at Volvo, fewer had a university education, and a lesser proportion was married or cohabitant at 
Table 1 Baseline characteristics for entire cohort and participants with incident MI and free of incident MI at follow up

\begin{tabular}{|c|c|c|c|}
\hline & $\begin{array}{l}\text { All analyzed participants at } \mathrm{T} 1 \\
(n=968)\end{array}$ & $\begin{array}{l}\text { Incident MI at T2 } \\
(n=84)\end{array}$ & $\begin{array}{l}\text { No MI at T2 } \\
(n=885)\end{array}$ \\
\hline Age at $\mathrm{T} 1$, mean $\pm \mathrm{SD}$, years & $47.7 \pm 1.5$ & $47.9 \pm 1.4$ & $47.7 \pm 1.5$ \\
\hline White-collared work, n (\%) & $591(61)$ & $42(50)$ & $549(62)$ \\
\hline Blue-collared work, n (\%) & $375(39)$ & $41(49)$ & $335(38)$ \\
\hline University education, $\mathrm{n}(\%)$ & $236(24)$ & $12(14)$ & $224(25)$ \\
\hline Married or cohabitant, $\mathrm{n}(\%)$ & $739(76)$ & $62(74)$ & $677(77)$ \\
\hline Social support index, mean $\pm \mathrm{SD}$ & $11.3 \pm 6.3$ & $10.3 \pm 4.6$ & $11.4 \pm 6.5$ \\
\hline Hypertension, n (\%) & $91(9.4)$ & $13(16)$ & $78(8.8)$ \\
\hline Body mass index, mean $\pm \mathrm{SD}, \mathrm{kg} / \mathrm{m}^{2}$ & $25.6 \pm 3.3$ & $26.7 \pm 3.2$ & $25.5 \pm 3.3$ \\
\hline Diabetes, $\mathrm{n}(\%)$ & $13(1.3)$ & $6(7.1)$ & $7(0.8)$ \\
\hline Framingham risk index score,mean $\pm \mathrm{SD}, 10$-year risk percentage & $9.1 \pm 5.8$ & $13.6 \pm 7.7$ & $8.6 \pm 5.4$ \\
\hline Active smoker, n (\%) & $270(28)$ & $44(52)$ & $226(26)$ \\
\hline Smoking in pack years, mean \pm SD & $11.4 \pm 13$ & $19.4 \pm 15$ & $10.7 \pm 12$ \\
\hline Alcohol consumption, mean $\pm \mathrm{SD}, \mathrm{g} /$ day & $7.42 \pm 8.3$ & $8.79 \pm 13.4$ & $7.29 \pm 7.7$ \\
\hline Exercise > $1 \mathrm{~h}$ per week, $\mathrm{n}(\%)$ & $664(69)$ & $54(64)$ & $610(69)$ \\
\hline Anxiety score, mean $\pm \mathrm{SD}, 1-9$ & $3.9 \pm 1.6$ & $4.0 \pm 1.7$ & $3.9 \pm 1.6$ \\
\hline Depression score, mean \pm SD, $1-9$ & $3.2 \pm 1.4$ & $3.2 \pm 1.5$ & $3.2 \pm 1.4$ \\
\hline Trait anger score, mean $\pm \mathrm{SD}, 10-40$ & $16.4 \pm 4.0$ & $16.8 \pm 4.6$ & $16.4 \pm 3.9$ \\
\hline
\end{tabular}

$S D$ standard deviation

Baseline characteristics for the entire cohort free of CHD at baseline (T1; n =968) and with distribution of two subcategories at follow up, T2: participants with incident MI $(n=84)$ and participants free of incident MI $(n=885)$. Continuous variables are presented with means and standard deviations. Dichotomous variables are presented with counts and percentages

T1. Rates of incident MI was markedly higher (24\%) in this subgroup at $\mathrm{T} 2$ than for the other two.

\section{Main outcome at T2: psychological variables}

For psychological variables, T1-reported anxiety, depression, and anger were similar between those men who later had an

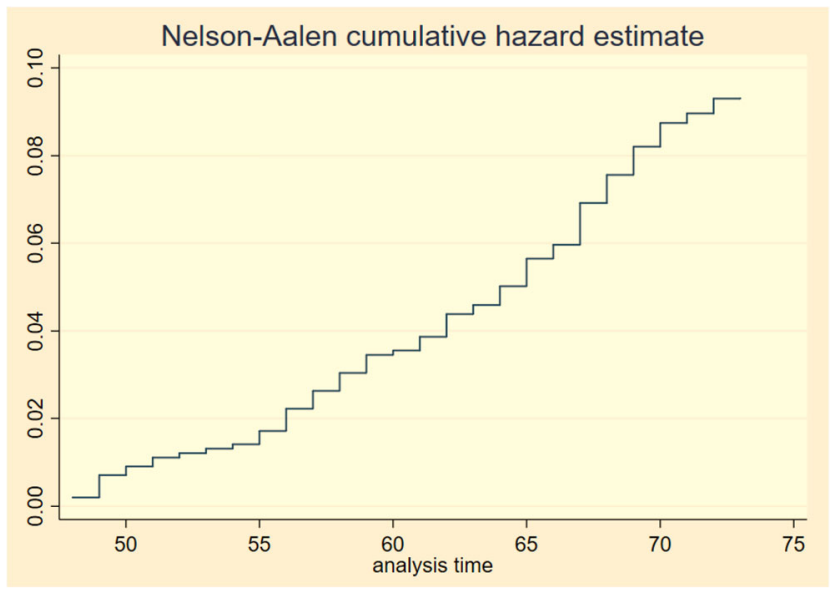

Fig. 2 Estimated cumulative incidence of myocardial infarction by age in the entire original cohort of 980 men during the observed time period (MIs = 89), calculated by a Nelson-Aalen cumulative hazard estimate incident MI and those who remained free of MI throughout the study (see Table 1). Principally, as Table 3 shows, none of the psychological variables was significantly associated with the outcome of incident MI. Covariate effects were further explored through multivariate logistic regression analyses, but were not found to have any relevant influence on outcome. However, some correlations between the psychological variables and other CHD risk factors were observed and are reported in Table 4. Between the psychological variables there were significant but weak correlations between anger and anxiety $(\mathrm{r}=0.29, p<0.001)$ and anger and depression $(\mathrm{r}=0.34$, $p<0.001)$ and a moderate significant correlation between depression and anxiety $(\mathrm{r}=0.51, p<0.001)$. Blue collar workers $(\mathrm{r}=-0.11, p<0.001)$ and those with a university level education $(\mathrm{r}=-0.11, p=0.001)$ were slightly less prone to anxiety. Anxiety was furthermore slightly negatively associated with BMI $(\mathrm{r}=-0.08, p=0.02)$. Those men scoring high on depression were marginally less likely to be married or cohabitating $(\mathrm{r}=-0.08, p=0.02)$ and scored somewhat lower on social support $(\mathrm{r}=-0.09, p<0.01)$. Both anger and depression had significant but weak correlations with smoking $(\mathrm{r}=0.10$, $p<0.01$ and $\mathrm{r}=0.06, p<0.05$, respectively). In turn, anger and anxiety were associated with having marginally higher alcohol consumption $(\mathrm{r}=0.09, p<0.01$ and $\mathrm{r}=0.07, p=0.03$, respectively). Other traditional CHD risk factors did not significantly correlate with any of the psychological variables. 
Table 2 Baseline (T1) characteristics for entire cohort as well as for subgroups according to responding status at follow up (T2)

\begin{tabular}{|c|c|c|c|c|}
\hline & $\begin{array}{l}\text { All analyzed participants } \\
\text { at } \mathrm{T} 1 \\
(\mathrm{n}=968)\end{array}$ & $\begin{array}{l}\text { Responders at } \\
\text { T2 } \\
(n=667)\end{array}$ & $\begin{array}{l}\text { Living non-responders } \\
\text { at T2 } \\
(n=215)\end{array}$ & $\begin{array}{l}\text { Deceased participants } \\
\text { at T2 } \\
(n=86)\end{array}$ \\
\hline Age at $\mathrm{T} 1$, mean $\pm \mathrm{SD}$, years & $47.7 \pm 1.5$ & $47.7 \pm 1.5$ & $47.6 \pm 1.5$ & $47.9 \pm 1.5$ \\
\hline White-collared work, n (\%) & $591(61)$ & $440(66)$ & $116(54)$ & $35(41)$ \\
\hline Blue-collared work, n (\%) & $375(39)$ & $224(34)$ & $101(47)$ & $51(59)$ \\
\hline University education, n (\%) & $236(24)$ & $169(25)$ & $55(26)$ & $12(14)$ \\
\hline Married or cohabitant, n (\%) & 739 (76) & $537(81)$ & $151(70)$ & $51(59)$ \\
\hline Social support index, mean $\pm \mathrm{SD}$ & $11.3 \pm 6.3$ & $11.7 \pm 7.0$ & $10.2 \pm 4.6$ & $11.4 \pm 4.8$ \\
\hline Hypertension, n (\%) & $91(9.4)$ & $53(7.9)$ & $22(10.2)$ & $16(19)$ \\
\hline Body mass index, mean $\pm \mathrm{SD}, \mathrm{kg} / \mathrm{m}^{2}$ & $25.6 \pm 3.3$ & $25.3 \pm 3.2$ & $26 \pm 3.3$ & $26.8 \pm 4.3$ \\
\hline Diabetes, n (\%) & $13(1.3)$ & $6(0.9)$ & $3(1.4)$ & $4(4.7)$ \\
\hline $\begin{array}{l}\text { Framingham risk index score, mean } \pm \mathrm{SD}, 10 \text {-year risk } \\
\text { percentage }\end{array}$ & $9.1 \pm 5.8$ & $8.4 \pm 5.1$ & $9.8 \pm 6.5$ & $12.8 \pm 8.1$ \\
\hline Active smoker, n (\%) & $270(28)$ & $159(24)$ & $69(32)$ & $42(49)$ \\
\hline Alcohol consumption, mean $\pm \mathrm{SD}, \mathrm{g} /$ day & $7.42 \pm 8.3$ & $7.49 \pm 8.2$ & $7.56 \pm 8.4$ & $6.53 \pm 8.8$ \\
\hline Exercise $>1 \mathrm{~h}$ per week, $\mathrm{n}(\%)$ & $664(69)$ & $469(70)$ & $141(66)$ & $54(63)$ \\
\hline Anxiety score, mean $\pm \mathrm{SD}, 1-9$ & $3.9 \pm 1.6$ & $3.9 \pm 1.6$ & $4.0 \pm 1.6$ & $3.7 \pm 1.7$ \\
\hline Depression score, mean \pm SD, $1-9$ & $3.2 \pm 1.4$ & $3.1 \pm 1.4$ & $3.3 \pm 1.3$ & $3.1 \pm 1.5$ \\
\hline Trait anger score, mean $\pm \mathrm{SD}, 10-40$ & $16.4 \pm 4.0$ & $16.2 \pm 3.9$ & $17 \pm 4.2$ & $16.5 \pm 3.9$ \\
\hline Incident myocardial infarction, $\mathrm{n}(\%)$ & $84(8.7)$ & $44(6.6)$ & $19(8.8)$ & $21(24)$ \\
\hline
\end{tabular}

$S D$ standard deviation

\section{Discussion}

Overall, our results could not support an association between depression, anxiety, or anger and an increased risk of MI for this initially healthy working sample of middle-age men. There were weak to moderate significant correlations between the psychological variables, and minor correlations between these factors and some of the behavioral covariates of CHD. No association was found between the psychological variables and the Framingham risk index score.

The scarce number of earlier studies on healthy homogenous cohorts exploring psychological factors in relation to CHD have shown disparate and inconclusive effects. In a large-scale cohort study conducted on Swedish men 18-

Table 3 Main outcome for each of the psychological variables

\begin{tabular}{lccc}
\hline & OR & $95 \% C I$ & $p$ value \\
\hline Trait anger, subscale & 1.03 & $0.97-1.08$ & 0.37 \\
Depression, single item & 1.01 & $0.86-1.19$ & 0.91 \\
Anxiety, single item & 1.02 & $0.89-1.17$ & 0.79 \\
\hline
\end{tabular}

$O R$ odds ratio, $C I$ confidence interval

Each of the predicted psychological factors as a continuous variable was tested against the binary outcome of incident myocardial infarction using logistic regression models. The result is presented as odds ratios with their 95\% confidence intervals and $\boldsymbol{p}$ values
20 years of age examined for military service with a follow up of 37 years, Janszky et al. (2010) found anxiety, but not depression, to independently predict MI. On the contrary, Ford et al. (1998) found clinical depression to be an independent risk factor for CHD in male medical students with a mean follow up of 37 years. The Whitehall II study, examining civil servants aged $35-55$ years, did not find any significant association between one time-assessment of depressive symptoms (Brunner et al. 2014; Nicholson et al. 2005), or anxiety (Nicholson et al. 2005) and CHD death or non-fatal MI, but did however report a dose-relation when looking at six repeated measures of depressive symptoms during 24 years (Brunner et al. 2014), examining the cumulative effect of increasing levels of depressive symptomatology.

We speculate that a main reason for failure to replicate earlier findings for these psychological factors is that our cohort was unexpectedly healthy, both physically and psychologically, at study entry. Low scores of initial psychological distress and what appears as a low number of MIs simply could have limited the possibility for predicted associations to appear. In this setting our sample size may have been too small. Indeed, occupational samples are known for providing a "healthy worker effect" ( $\mathrm{Li}$ and Sung 1999). In keeping with this, total mortality in the cohort was lower than expected (Dimberg et al. 2019), amounting to 4.8 per 1000 person years, whereas the official death rate for Swedish males aged 50 was 6.4 in 2015 (Statistics Sweden 2016). Furthermore, the 
Table 4 Correlations between psychological variables and covariates of coronary heart disease

\begin{tabular}{|c|c|c|c|c|c|c|}
\hline & $\begin{array}{l}\text { Anger } \\
r\end{array}$ & $p \leq$ & $\begin{array}{l}\text { Depression } \\
r\end{array}$ & $p \leq$ & $\begin{array}{l}\text { Anxiety } \\
r\end{array}$ & $p \leq$ \\
\hline Anger & 1.00 & & & & & \\
\hline Depression & 0.34 & 0.001 & 1.00 & & & \\
\hline Anxiety & 0.29 & 0.001 & 0.51 & 0.001 & 1.00 & \\
\hline Blue-collar work & 0.04 & ns & 0.01 & ns & -0.11 & 0.001 \\
\hline University education & -0.02 & ns & -0.04 & ns & -0.11 & 0.001 \\
\hline Married or cohabitant & -0.01 & ns & -0.08 & 0.05 & 0.02 & ns \\
\hline Social support index & 0.01 & ns & -0.09 & 0.01 & -0.04 & ns \\
\hline Smoking & 0.10 & 0.01 & 0.06 & 0.05 & -0.02 & ns \\
\hline Total alcohol consumption, g/day & 0.09 & 0.01 & 0.05 & $\mathrm{~ns}$ & 0.07 & 0.05 \\
\hline Body mass index (BMI) & 0.04 & $\mathrm{~ns}$ & -0.03 & $\mathrm{~ns}$ & -0.08 & 0.05 \\
\hline Less than $1 \mathrm{~h}$ ofexercise per week & -0.06 & ns & 0.01 & ns & 0.04 & ns \\
\hline Systolic blood pressure & -0.05 & ns & -0.05 & ns & -0.03 & ns \\
\hline Probable left ventricularhypertrophy according to Sokolow & 0.00 & ns & 0.02 & ns & -0.04 & ns \\
\hline Total cholesterol & 0.04 & ns & -0.02 & ns & -0.03 & ns \\
\hline Heart rate & 0.01 & ns & 0.01 & ns & -0.01 & ns \\
\hline Fasting blood glucose & 0.00 & ns & 0.05 & ns & 0.05 & ns \\
\hline Framingham risk index score & -0.01 & ns & 0.00 & ns & -0.05 & ns \\
\hline
\end{tabular}

$r$ Pearson correlation coefficient, $n s$ non-significant

Correlation analyses were performed between each of the predicted psychological variables and covariates of CHD, and are presented below with Pearson correlation coefficients (r) and their $p$ values. Significant associations with p-values at the $0.05,0.01$ and 0.001 level are presented

average calculated 10-year risk for MI according to the FRI was $9.1 \%$ at T1, which amounts to a predicted number of 88 MIs after 10 years, suggesting that the number of incident events of MIs in this cohort over 22 years was considerably lower than expected. Additionally, the Volvo Corporation is well-known for having implemented a more flattened workplace organization in the early 1990s (Dimberg 1996). A more decentralized hierarchy increased distribution of responsibility and control among workers, which might have further increased the well-being in the cohort.

Moving to psychological measurements, the average scores of anxiety and depression appear to have been in the lower range. We used singular questions to define depression and anxiety in our baseline survey. While this is a significant limitation, the questions did correlate significantly with the psychological well-being index (PGWB) used in the 5-year follow-up presented in the study by Rose et al. (2006) where a higher score of anxiety and depression at baseline was significantly associated with poorer psychological well-being at follow-up. For depression, this study found correlations for total well-being $(\mathrm{r}=0.415 ; p<0.0001)$ as well as with the index' sub-scale for depression $(\mathrm{r}=0.310 ; p<0.0001)$. When it comes to anger, the Trait Anger subscale (mean cohort score $16.4 \pm$ SD 4.0, range 10-40), has been previously applied in CHD research, e.g., in a study by Williams et al. (2000) where the average group Trait Anger score was 16.0 ( \pm SD 3.7) with significant found effects in regard to CHD outcome, suggesting that the level of anger in itself was not the principal reason for the absence of predicted effect in our study.

An earlier study (Dimberg et al. 2019) conducted on the 22-year follow-up data for this current Volvo cohort similarly found traditional CHD risk factors (age, gender, tobacco smoking, blood pressure, cholesterol lipoproteins, body mass index, diabetes mellitus, left ventricular hypertrophy) to have a rather weak role in explaining incidence of $\mathrm{MI}$ in this cohort, with the Framingham risk score as the strongest predictor of MI, explaining $5.3 \%$ of the risk variation. Other significant risk factors were low education and manual labor. The authors proposed that one possible reason for the weak relationships might be that participants had changed their health behaviors over the follow up period, which also could be an applicable explanation here. Findings presented in another longitudinal Swedish study of 50-year-old men followed for 50 years showed distinctly decreased rates of cigarette smokers over time, also likely to apply to our cohort (Zhong et al. 2017).

In the light of a relevant debate on the failure to replicate studies in social psychology (Dominus 2017), another possible explanation could be that in actuality no associations between suggested psychological factors and MI exists, in which case earlier findings pointing to such effects could be confounded by covariate effects or poor study design. However, this seems unlikely considering convincing results from recent 
meta-analyses on heterogeneous samples (Roest et al. 2010; Wu and Kling 2016). However, it may still be true that for healthier populations, such as the present cohort, there could for example be significant protective effects at play.

Correlation analyses provided some clues to elucidate the relationships between anger, depression, and anxiety in CHD research. As expected, there were significant correlations between the psychological variables indicating comorbidity and/ or construct overlap and, although these were weak to moderate in size, this finding implies that research on these factors as risk factors for CHD indeed should, as suggested (Suls and Bunde 2005), simultaneously focus on all three factors in order to clarify to what extent they represent independent risk factors for CHD. Concerning associations with adverse health behaviors, these were inadequate in size to explain possible associations between psychological variables and CHD.

\section{Limitations}

Several study limitations exist. First, the cohort was limited to an occupational sample of Caucasian middle-aged men, limiting generalization of the findings to women, or other ethnic groups or ages, where results might be different.

The study was not initially dimensioned to evaluate psychological variables but rather to distinguish the predictive effects of traditional risk factors between the Swedish and French Coeur cohorts, seriously limiting the possibility to draw extensive conclusions from a null finding.

Future studies of this sort should ideally use validated and matching scales to measure all three psychological variables. If possible, it would additionally be meaningful for cohort studies to re-examine health behaviors and CHD risk factor prevalence at follow up with the purpose to explore to what extent changes in these variables influence between-study differences in outcome.

\section{Conclusions}

In this cohort study of a homogeneous healthy sample of 968 working middle-aged men, results failed to show that anxiety, anger, or depression were risk factors for myocardial infarction after 22-year follow-up. Sample restrictions limit generalizability to other types of cohorts; however, a plausible reason for failure to replicate earlier findings from community and patient samples could be that the study was not primarily designed to explore these connections and the cohort was in fact too healthy for relationships to appear. Consistent with the present study, the relatively few studies conducted on homogeneous healthy employed samples show inconclusive effects, suggesting a need for further research on these associations in these healthier samples. As expected there was some overlap between the psychological variables suggesting that anger, anxiety, and depression should indeed in the future be studied simultaneously as risk factors in order to elucidate their putative independent effects on CHD.

Acknowledgements The authors acknowledge financial contributions for the original Renault-Volvo Coeur study from the occupational departments of Renault and Volvo automotive companies as well as a grant from the Volvo Research Foundation H 92-37. We sincerely appreciate all previous work that has paved the way for this paper. In addition, the more recent works by Mohammed Hashem and Per Enqvist have been valuable for this publication.

Authors' contributions Dr. Lennart Dimberg, who at the time worked as an occupational physician at the Volvo Corporation, was involved in the design of and oversaw the initial Renault-Volvo Coeur Study. Dr. Dimberg also oversaw the collection of follow-up data at 22 years. Rebecca Vella executed the analysis and compiled the results of the current study as a master thesis student under the supervision of Dr. Dimberg and guidance of Professor Richard P Sloan. Professor Bo Eriksson oversaw and contributed to the statistical method and analysis. All authors contributed to the interpretation of data. The first draft of this manuscript was written by Rebecca Vella and was subsequently read and revised by all authors. Unfortunately, professor Bo Eriksson recently died and has therefore not read the final manuscript.

Funding Open access funding provided by University of Gothenburg. The Volvo branch of the original Renault-Volvo Coeur project was financed by a grant from the Volvo Research Foundation in 1992 H92:37. The enterprises had no influence on the interpretation of the data.

Availability of data and material Data would be available upon request.

Code availability All codes are anonymized and real IDs will not be made available.

\section{Declarations}

Conflicts of interest/competing interests The authors have no conflicts of interest to declare that are relevant to the content of this article.

Ethics approval The Research Ethics Committee of Gothenburg University approved the original study protocol and the consent to participate form on 11 February 1993 (Dnr. 23-93). This study was performed in line with the principles of the Declaration of Helsinki. For the present study, a cover letter reminded participants of their participation in the R-V Coeur Study, stated the aims of the follow up, and emphasized that continued participation was voluntary and confidential. A form of written consent asked participants to approve validation of reported health information by use of medical records. The study reporting was executed in line with STROBE guidelines for observational studies.

Consent to participate All participants of the baseline study in 1993 were informed that only aggregated data would be published and agreed upon participation.

Consent for publication For the present study, the need to consent was waivered by the ethics committee since only register information was collected and all data are anonymized.

Informed consent Informed consent was obtained from all included study participants. 
Open Access This article is licensed under a Creative Commons Attribution 4.0 International License, which permits use, sharing, adaptation, distribution and reproduction in any medium or format, as long as you give appropriate credit to the original author(s) and the source, provide a link to the Creative Commons licence, and indicate if changes were made. The images or other third party material in this article are included in the article's Creative Commons licence, unless indicated otherwise in a credit line to the material. If material is not included in the article's Creative Commons licence and your intended use is not permitted by statutory regulation or exceeds the permitted use, you will need to obtain permission directly from the copyright holder. To view a copy of this licence, visit http://creativecommons.org/licenses/by/4.0/.

\section{References}

Albert CM, Chae CU, Rexrode KM, Manson JE, Kawachi I (2005) Phobic anxiety and risk of coronary heart disease and sudden cardiac death among women. Circulation 111(4):480-487. https://doi.org/ 10.1161/01.cir.0000153813.64165.5d

Anderson KM, Wilson PW, Odell PM, Kannel WB (1991) An updated coronary risk profile. A statement for health professionals. Circulation 83(1):356-362. https://doi.org/10.1161/01.cir.83.1.356

Barefoot JC, Schroll M (1996) Symptoms of depression, acute myocardial infarction, and total mortality in a community sample. Circulation 93(11):1976-1980. https://doi.org/10.1161/01.cir.93. 11.1976

Beck A (1987) Manual for the Beck depression inventory. The Psychological Corporation, San Antonio

Beck AS, Steer RA, Garbin MG (1988) Psychometric properties of the beck depression inventory: twenty-five years of evaluation. Clin Psychol Rev 8:77-100. https://doi.org/10.1016/0272-7358(88) 90050-5

Blaha MJ, Whelton SP, Al Rifai M, Dardari Z, Shaw LJ, Al-Mallah MH, Matsushita K, Rozanski A, Rumberger JA, Berman DS, Budoff MJ, Miedema MD, Nasir K, Cainzos-Achirica M (2021) Comparing risk scores in the prediction of coronary and cardiovascular deaths: coronary artery calcium consortium. JACC Cardiovasc Imaging 14(2): 411-421. https://doi.org/10.1016/j.jcmg.2019.12.010

Bleil ME, McCaffery JM, Muldoon MF, Sutton-Tyrrell K, Manuck SB (2004) Anger-related personality traits and carotid artery atherosclerosis in untreated hypertensive men. Psychosom Med 66(5):633639. https://doi.org/10.1097/01.psy.0000138128.68838.50

Boyle SH, Michalek JE, Suarez EC (2006) Covariation of psychological attributes and incident coronary heart disease in U.S. air Force veterans of the Vietnam war. Psychosom Med 68(6):844-850. https:// doi.org/10.1097/01.psy.0000240779.55022.ff

Brindle P, Beswick A, Fahey T, Ebrahim S (2006) Accuracy and impact of risk assessment in the primary prevention of cardiovascular disease: a systematic review. Heart 92(12):1752-1759. https://doi.org/ 10.1136/hrt.2006.087932

Brindle P, Emberson J, Lampe F, Walker M, Whincup P, Fahey T et al (2003) Predictive accuracy of the Framingham coronary risk score in British men: prospective cohort study. BMJ (Clinical research ed) 327(7426):1267. https://doi.org/10.1136/bmj.327.7426.1267

Brunner EJ, Shipley MJ, Britton AR, Stansfeld SA, Heuschmann PU, Rudd AG, Wolfe CD, Singh-Manoux A, Kivimaki M (2014) Depressive disorder, coronary heart disease, and stroke: doseresponse and reverse causation effects in the Whitehall II cohort study. Eur J Prev Cardiol 21(3):340-346. https://doi.org/10.1177/ 2047487314520785

Celano CM, Millstein RA, Bedoya CA, Healy BC, Roest AM, Huffman JC (2015) Association between anxiety and mortality in patients with coronary artery disease: a meta-analysis. Am Heart J 170(6): 1105-1115. https://doi.org/10.1016/j.ahj.2015.09.013

Chalmers JA, Quintana DS, Abbott MJ, Kemp AH (2014) Anxiety disorders are associated with reduced heart rate variability: a metaanalysis. Front Psychiatry 5:80. https://doi.org/10.3389/fpsyt.2014. 00080

Chida Y, Steptoe A (2009) The association of anger and hostility with future coronary heart disease: a meta-analytic review of prospective evidence. J Am Coll Cardiol 53(11):936-946. https://doi.org/10. 1016/j.jacc.2008.11.044

Das S, O'Keefe JH (2006) Behavioral cardiology: recognizing and addressing the profound impact of psychosocial stress on cardiovascular health. Curr Atheroscler Rep 8(2):111-118. https://doi.org/10. 1007/s11883-006-0048-2

Denarié N, Simon A, Chironi G, Gariepy J, Kumlin L, Massonneau M, Lanoiselée C, Dimberg L, Levenson J (2001) Difference in carotid artery wall structure between Swedish and French men at low and high coronary risk. Stroke 32(8):1775-1779. https://doi.org/10. 1161/01.str.32.8.1775

Dimberg L (1996) Overview of ergonomic research and some practical applications in Sweden. In: Bhattacharya AMJ (ed) Occupational ergonomics. Marcel Decker Inc, New York, pp 733-749

Dimberg L, Eriksson B, Hashem M (2019) Myocardial infarction and death findings from a 22-year follow-up of a cohort of 980 employed Swedish men. Public Health 175:148-155. https://doi. org/10.1016/j.puhe.2019.07.006

Dominus S (2017) When the revolution came for Amy Cuddy. The New York Times. https://www.nytimes.com/2017/10/18/magazine/ when-the-revolution-came-for-amy-cuddy.html. Accessed 18 October 2017

Elwood LS, Wolitzky-Taylor K, Olatunji BO (2012) Measurement of anxious traits: a contemporary review and synthesis. Anxiety Stress Coping 25(6):647-666. https://doi.org/10.1080/10615806. 2011.582949

Everson-Rose SA, Lewis TT (2005) Psychosocial factors and cardiovascular diseases. Annu Rev Public Health 26:469-500. https://doi.org/ 10.1146/annurev.publhealth.26.021304.144542

Fishta A, Backé EM (2015) Psychosocial stress at work and cardivascular diseases: an overview of systematic reviews. Int Arch Occup Environ Health 88:997-1014. https://doi.org/10.1007/s00420-0151019-0

Ford DE, Mead LA, Chang PP, Cooper-Patrick L, Wang NY, Klag MJ (1998) Depression is a risk factor for coronary artery disease in men: the precursors study. Arch Intern Med 158(13):1422-1426. https:// doi.org/10.1001/archinte.158.13.1422

Forgays DG, Forgays DK, Spielberger CD (1997) Factor structure of the state-trait anger expression inventory. J Pers Assess 69(3):497-507. https://doi.org/10.1207/s15327752jpa6903_5

Gafarov VV, Gromova HA, Gagulin IV, Ekimova YC, Santrapinskiy DK (2007) Arterial hypertension, myocardial infarction and stroke: risk of development and psychosocial factors. Alaska Med 49(2 Suppl): $117-119$

Hense HW, Schulte H, Lowel H, Assmann G, Keil U (2003) Framingham risk function overestimates risk of coronary heart disease in men and women from Germany-results from the MONICA Augsburg and the PROCAM cohorts. Eur Heart J 24(10):937-945. https://doi.org/ 10.1016/s0195-668x(03)00081-2

Hill AB (1965) The environment and disease: association or causation? J R Soc Med 108(1):32-37.https://doi.org/10.1177/ 0141076814562718

Hubert HB, Feinleib M, McNamara PM, Castelli WP (1983) Obesity as an independent risk factor for cardiovascular disease: a 26-year follow-up of participants in the Framingham heart study. Circulation 67(5):968-977. https://doi.org/10.1161/01.cir.67.5.968 
Insull W Jr (2009) The pathology of atherosclerosis: plaque development and plaque responses to medical treatment. Am J Med 122(1 Suppl): S3-S14. https://doi.org/10.1016/j.amjmed.2008.10.013

Janszky I, Ahnve S, Lundberg I, Hemmingsson T (2010) Early-onset depression, anxiety, and risk of subsequent coronary heart disease: 37-year follow-up of 49,321 young Swedish men. J Am Coll Cardiol 56(1):31-37. https://doi.org/10.1016/j.jacc.2010.03.033

Kemp AH, Quintana DS, Felmingham KL, Matthews S, Jelinek HF (2012) Depression, comorbid anxiety disorders, and heart rate variability in physically healthy, unmedicated patients: implications for cardiovascular risk. PLoS One 7(2):e30777. https://doi.org/10.1371/ journal.pone.0030777

Kivimäki M, Virtanen M, Elovainio M, Kouvonen A, Väänänen A, Vahtera J (2006) Work stress in the etiology of coronary heart disease - a meta-analysis. Scand J Work Environ Health 32(6):431442. https://doi.org/10.5271/sjweh.1049

Krueger RF (1999) The structure of common mental disorders. Arch Gen Psychiatry 56(10):921-926. https://doi.org/10.1001/archpsyc.56. 10.921

Kubzansky LD, Cole SR, Kawachi I, Vokonas P, Sparrow D (2006) Shared and unique contributions of anger, anxiety, and depression to coronary heart disease: a prospective study in the normative aging study. Ann Behav Med 31(1):21-29. https://doi.org/10.1207/ s15324796abm3101_5

Kumlin L, Dimberg L, Marin P (1997) Ratio of abdominal sagittal diameter to height is strong indicator of coronary risk. BMJ (Clinical research ed) 314(7083):830. https://doi.org/10.1136/bmj.314.7083. 830

Kumlin L, Latscha G, Orth-Gomér K, Dimberg L, Lanoiselée C, Simon A, Eriksson B, Coeur Study Group (2001) Marital status and cardiovascular risk in French and Swedish automotive industry workers-cross sectional results from the Renault-Volvo Coeur study. J Intern Med 249(4):315-323. https://doi.org/10.1046/j. 1365-2796.2001.00817.x

Law MR, Wald NJ (2003) Environmental tobacco smoke and ischemic heart disease. Prog Cardiovasc Dis 46(1):31-38. https://doi.org/10. 1016/s0033-0620(03)00078-1

Lesperance F, Frasure-Smith N, Talajic M, Bourassa MG (2002) Fiveyear risk of cardiac mortality in relation to initial severity and oneyear changes in depression symptoms after myocardial infarction. Circulation 105(9):1049-1053. https://doi.org/10.1161/hc0902. 104707

Li CY, Sung FC (1999) A review of the healthy worker effect in occupational epidemiology. Occup Med (Lond) 49(4):225-229. https:// doi.org/10.1093/occmed/49.4.225

Martin R, Watson D, Wan CK (2000) A three-factor model of trait anger: dimensions of affect, behavior and cognition. J Pers 68(5):869-897. https://doi.org/10.1111/1467-6494.00119

Matthews KA, Owens JF, Kuller LH, Sutton-Tyrrell K, JansenMcWilliams L (1998) Are hostility and anxiety associated with carotid atherosclerosis in healthy postmenopausal women? Psychosom Med 60(5):633-638. https://doi.org/10.1097/ 00006842-199809000-00021

Mendes de Leon CF, Kop WJ, de Swart HB, Bar FW, Appels AP (1996) Psychosocial characteristics and recurrent events after percutaneous transluminal coronary angioplasty. Am J Cardiol 77(4):252-255. https://doi.org/10.1016/s0002-9149(97)89388-5

Mineka S, Watson D, Clark LA (1998) Comorbidity of anxiety and unipolar mood disorders. Annu Rev Psychol 49:377-412. https://doi. org/10.1146/annurev.psych.49.1.377

Mykletun A, Bjerkeset O, Dewey M, Prince M, Overland S, Stewart R (2007) Anxiety, depression, and cause-specific mortality: the HUNT study. Psychosom Med 69(4):323-331. https://doi.org/10.1097/psy. 0b013e31803cb862

Nicholson A, Fuhrer R, Marmot M (2005) Psychological distress as a predictor of CHD events in men: the effect of persistence and components of risk. Psychosom Med 67(4):522-530. https://doi. org/10.1097/01.psy.0000171159.86446.9e

Nicholson A, Kuper H, Hemingway H (2006) Depression as an aetiologic and prognostic factor in coronary heart disease: a meta-analysis of 6362 events among 146538 participants in 54 observational studies. Eur Heart J 27(23):2763-2774. https://doi.org/10.1093/eurheartj/ ehl338

Pencina MJ, Navar AM, Wojdyla D, Sanchez RJ, Khan I, Elassal J, D'Agostino RB, Sr Peterson ED, Sniderman AD (2019) Quantifying importance of major risk factors for coronary heart disease. Circulation 139(13):1603-1611. https://doi.org/10.1161/ CIRCULATIONAHA.117.031855

Pollitt RA, Daniel M, Kaufman JS, Lynch JW, Salonen JT, Kaplan GA (2005) Mediation and modification of the association between hopelessness, hostility, and progression of carotid atherosclerosis. J Behav Med 28(1):53-64. https://doi.org/10.1007/s10865-0052563-y

Räikkönen K, Matthews KA, Sutton-Tyrrell K, Kuller LH (2004) Trait anger and the metabolic syndrome predict progression of carotid atherosclerosis in healthy middle-aged women. Psychosom Med 66(6):903-908. https://doi.org/10.1097/01.psy.0000143638.31297. 11

Roest AM, Martens EJ, de Jonge P, Denollet J (2010) Anxiety and risk of incident coronary heart disease: a meta-analysis. J Am Coll Cardiol 56(1):38-46. https://doi.org/10.1016/j.jacc.2010.03.034

Rose G, Bengtsson C, Dimberg L, Kumlin L, Eriksson B (1998) Life events, mood, mental strain and cardiovascular risk factors in Swedish middle-aged men. Data from the Swedish part of the Renault/Volvo Coeur study. Occup Med (Lond) 48(5):329-336. https://doi.org/10.1093/occmed/48.5.329

Rose G, Kumlin L, Dimberg L, Bengtsson C, Orth-Gomer K, Cai X (2006) Work-related life events, psychological well-being and cardiovascular risk factors in male Swedish automotive workers. Occup Med (Lond) 56(6):386-392. https://doi.org/10.1093/occmed/ kq1037

Rosengren A, Hawken S, Ounpuu S, Sliwa K, Zubaid M, Almahmeed WA, Blackett KN, Sitthi-amorn C, Sato H, Yusuf S, INTERHEART investigators (2004) Association of psychosocial risk factors with risk of acute myocardial infarction in 11119 cases and 13648 controls from 52 countries (the INTERHEART study): case-control study. Lancet 364(9438):953-962. https://doi.org/10.1016/s01406736(04)17019-0

Rozanski A, Blumenthal JA, Davidson KW, Saab PG, Kubzansky L (2005) The epidemiology, pathophysiology, and management of psychosocial risk factors in cardiac practice: the emerging field of behavioral cardiology. J Am Coll Cardiol 45(5):637-651. https:// doi.org/10.1016/j.jacc.2004.12.005

Rozanski A, Blumenthal JA, Kaplan J (1999) Impact of psychological factors on the pathogenesis of cardiovascular disease and implications for therapy. Circulation 99(16):2192-2217. https://doi.org/10. 1161/01.cir.99.16.2192

Santos IS, Bittencourt MS, Rocco PT, Pereira AC, Barreto SM, Brunoni AR, Goulart AC, Blaha MJ, Lotufo PA, Bensenor IM (2016) Relation of anxiety and depressive symptoms to coronary artery calcium (from the ELSA-Brasil baseline data). Am J Cardiol 118(2):183-187. https://doi.org/10.1016/j.amjcard.2016.04.048

Santos IS, Goulart AC, Brunoni AR, Kemp AH, Lotufo PA, Bensenor IM (2015) Anxiety and depressive symptoms are associated with higher carotid intima-media thickness. Cross-sectional analysis from ELSA-Brasil baseline data. Atherosclerosis 240(2):529-534. https://doi.org/10.1016/j.atherosclerosis.2015.04.800

Schulman JK, Stromberg S (2007) On the value of doing nothing: anger and cardiovascular disease in clinical practice. Cardiol Rev 15(3): 123-132. https://doi.org/10.1097/01.crd.0000246318.59658.25

Shen BJ, Avivi YE, Todaro JF, Spiro A 3rd, Laurenceau JP, Ward KD, Niaura R (2008) Anxiety characteristics independently and 
prospectively predict myocardial infarction in men the unique contribution of anxiety among psychologic factors. J Am Coll Cardiol 51(2):113-119. https://doi.org/10.1016/j.jacc.2007.09.033

Simon A, Dimberg L, Levenson J, Lanoiselée C, Massonneau M, Eriksson B, Jern S, Kumlin L, Marin P, Dahlöf B, Hansson L, Björntorp P (1997) Comparison of cardiovascular risk profile between male employees of two automotives companies in France and Sweden. The Coeur project group. Eur J Epidemiol 13(8):885-891. https://doi.org/10.1023/a:1007428624757

Sloan RP, Shapiro PA, Bigger JT Jr, Bagiella E, Steinman RC, Gorman JM (1994) Cardiac autonomic control and hostility in healthy subjects. Am J Cardiol 74(3):298-300. https://doi.org/10.1016/00029149(94)90382-4

Spielberger C (1988) Manual for the state-trait anger expression inventory (STAXI). Psychological Assessment Resources, Odessa

Spielberger CD, Gorsuch RL, Lushene R, Vagg PR, Jacobs GA (1983) Manual for the state-trait anxiety inventory (form Y). Mind Garden, Palo Alto

Statistics Sweden (2016) Demographic report 16:2, life expectancy and mortality in different social groups. Statistics Sweden, Forecast Institute, Stockholm

Suls J (2013) Anger and the heart: perspectives on cardiac risk, mechanisms and interventions. Prog Cardiovasc Dis 55(6):538-547. https://doi.org/10.1016/j.pcad.2013.03.002

Suls J, Bunde J (2005) Anger, anxiety, and depression as risk factors for cardiovascular disease: the problems and implications of overlapping affective dispositions. Psychol Bull 131(2):260-300. https:// doi.org/10.1037/0033-2909.131.2.260

SWEDEHEART (2017). http://www.ucr.uu.se/swedeheart/. Accessed 16 October 2017

Tunstall-Pedoe H (1988) Autres pays, autres moeurs - theories on why the French have less heart disease than the British. BMJ (Clinical research ed) 297:1559-1560. https://doi.org/10.1136/bmj.297.6663. 1559

Tunstall-Pedoe H, Kuulasmaa K, Amouyel P, Arveiler D, Rajakangas AM, Pajak A (1994) Myocardial infarction and coronary deaths in the World Health Organization MONICA project. Registration procedures, event rates, and case-fatality rates in 38 populations from 21 countries in four continents. Circulation 90(1):583-612. https:// doi.org/10.1161/01.cir.90.1.583
U.S. Department of Health and Human Services (2010) How tobacco smoke causes disease: the biology and behavioral basis for smoking-attributable disease: a report of the surgeon general. Atlanta, GA: U.S. Department of Health and Human Services, Centers for Disease Control and Prevention, National Center for Chronic Disease Prevention and Health Promotion, Office on Smoking and Health. 6, Cardiovascular Diseases. https://www. ncbi.nlm.nih.gov/books/NBK53012/. Accessed 18 October 2017

von Elm E, Altman DG, Egger M, Pocock SJ, Gotzsche PC, Vandenbroucke JP (2008) The strengthening the reporting of observational studies in epidemiology (STROBE) statement: guidelines for reporting observational studies. J Clin Epidemiol 61(4):344349. https://doi.org/10.1016/j.jclinepi.2007.11.008

Whang W, Kubzansky LD, Kawachi I, Rexrode KM, Kroenke CH, Glynn RJ, Garan H, Albert CM (2009) Depression and risk of sudden cardiac death and coronary heart disease in women: results from the Nurses' health study. J Am Coll Cardiol 53(11):950-958. https:// doi.org/10.1016/j.jacc.2008.10.060

Williams JE, Paton CC, Siegler IC, Eigenbrodt ML, Nieto FJ, Tyroler HA (2000) Anger proneness predicts coronary heart disease risk: prospective analysis from the atherosclerosis risk in communities (ARIC) study. Circulation 101(17):2034-2039. https://doi.org/10. 1161/01.cir.101.17.2034

World Health Organization (2017) Classification of diseases. http://www. who.int/classifications/icd/en/. WHO. Accessed 18 October 2017

Wu Q, Kling JM (2016) Depression and the risk of myocardial infarction and coronary death: a meta-analysis of prospective cohort studies. Medicine (Baltimore) 95(6):e2815. https://doi.org/10.1097/md. 0000000000002815

Zhong Y, Rosengren A, Fu M, Welin L, Welin C, Caidahl K, Mandalenakis Z, Dellborg M, Svärdsudd K, Hansson P-O (2017) Secular changes in cardiovascular risk factors in Swedish 50-yearold men over a 50-year period: the study of men born in 1913, 1923, 1933, 1943, 1953 and 1963. Eur J Prev Cardiol 24(6):612-620. https://doi.org/10.1177/2047487316676905

Publisher's note Springer Nature remains neutral with regard to jurisdictional claims in published maps and institutional affiliations. 